\title{
Non-pulsatile blood flow is associated with enhanced cerebrovascular carbon dioxide reactivity and an attenuated relationship between cerebral blood flow and regional brain oxygenation
}

Cecilia Maria Veraar ${ }^{1}$, Harald Rinösl ${ }^{2}$, Karina Kühn $^{3}$, Keso Skhirtladze-Dworschak' ${ }^{1}$ Alessia Felli', Mohamed Mouhieddine ${ }^{1}$, Johannes Menger ${ }^{1}$, Ekaterina Pataraia ${ }^{4}$, Hendrik Jan Ankersmit ${ }^{5}$ and Martin Dworschak ${ }^{1 *}$

\begin{abstract}
Background: Systemic blood flow in patients on extracorporeal assist devices is frequently not or only minimally pulsatile. Loss of pulsatile brain perfusion, however, has been implicated in neurological complications. Furthermore, the adverse effects of absent pulsatility on the cerebral microcirculation are modulated similarly as $\mathrm{CO}_{2}$ vasoreactivity in resistance vessels. During support with an extracorporeal assist device swings in arterial carbon dioxide partial pressures $\left(\mathrm{PaCO}_{2}\right)$ that determine cerebral oxygen delivery are not uncommon-especially when $\mathrm{CO}_{2}$ is eliminated by the respirator as well as via the gas exchanger of an extracorporeal membrane oxygenation machine. We, therefore, investigated whether non-pulsatile flow affects cerebrovascular $\mathrm{CO}_{2}$ reactivity (CVR) and regional brain oxygenation $\left(\mathrm{rSO}_{2}\right)$.

Methods: In this prospective, single-centre case-control trial, we studied 32 patients undergoing elective cardiac surgery. Blood flow velocity in the middle cerebral artery (MCAv) as well as $\mathrm{rSO}_{2}$ was determined during step changes of $\mathrm{PaCO}_{2}$ between 30,40, and $50 \mathrm{mmHg}$. Measurements were conducted on cardiopulmonary bypass during non-pulsatile and postoperatively under pulsatile blood flow at comparable test conditions. Corresponding changes of $\mathrm{CVR}$ and concomitant $\mathrm{rSO}_{2}$ alterations were determined for each flow mode. Each patient served as her own control.

Results: MCAv was generally lower during hypocapnia than during normocapnia and hypercapnia $(p<0.0001)$. However, the MCAv/PaCO 2 slope during non-pulsatile flow was $14.4 \mathrm{~cm} / \mathrm{s} / \mathrm{mmHg}[\mathrm{Cl} 11.8-16.9]$ and $10.4 \mathrm{~cm} / \mathrm{s} /$ $\mathrm{mmHg}[\mathrm{Cl} 7.9-13.0]$ after return of pulsatility $(p=0.03)$. During hypocapnia, non-pulsatile CVR $(4.3 \pm 1.7 \% / \mathrm{mmHg})$ was higher than pulsatile CVR $(3.1 \pm 1.3 \% / \mathrm{mmHg}, p=0.01)$. Independent of the flow mode, we observed a decline in $\mathrm{rSO} 2$ during hypocapnia and a corresponding rise during hypercapnia $(p<0.0001)$. However, the relationship between $\Delta \mathrm{rSO}_{2}$ and $\triangle \mathrm{MCAv}$ was less pronounced during non-pulsatile flow.

(Continued on next page)
\end{abstract}

\footnotetext{
* Correspondence: martin.dworschak@meduniwien.ac.at

'Division of Cardiothoracic and Vascular Anaesthesia and Intensive Care

Medicine, Department of Anaesthesia, Intensive Care Medicine, and Pain

Medicine, Vienna General Hospital, Medical University of Vienna, Waehringer

Guertel 18-20, 1090 Vienna, Austria

Full list of author information is available at the end of the article
}

(c) The Author(s). 2019 Open Access This article is distributed under the terms of the Creative Commons Attribution 4.0 International License (http://creativecommons.org/licenses/by/4.0/), which permits unrestricted use, distribution, and reproduction in any medium, provided you give appropriate credit to the original author(s) and the source, provide a link to the Creative Commons license, and indicate if changes were made. The Creative Commons Public Domain Dedication waiver (http://creativecommons.org/publicdomain/zero/1.0/) applies to the data made available in this article, unless otherwise stated. 


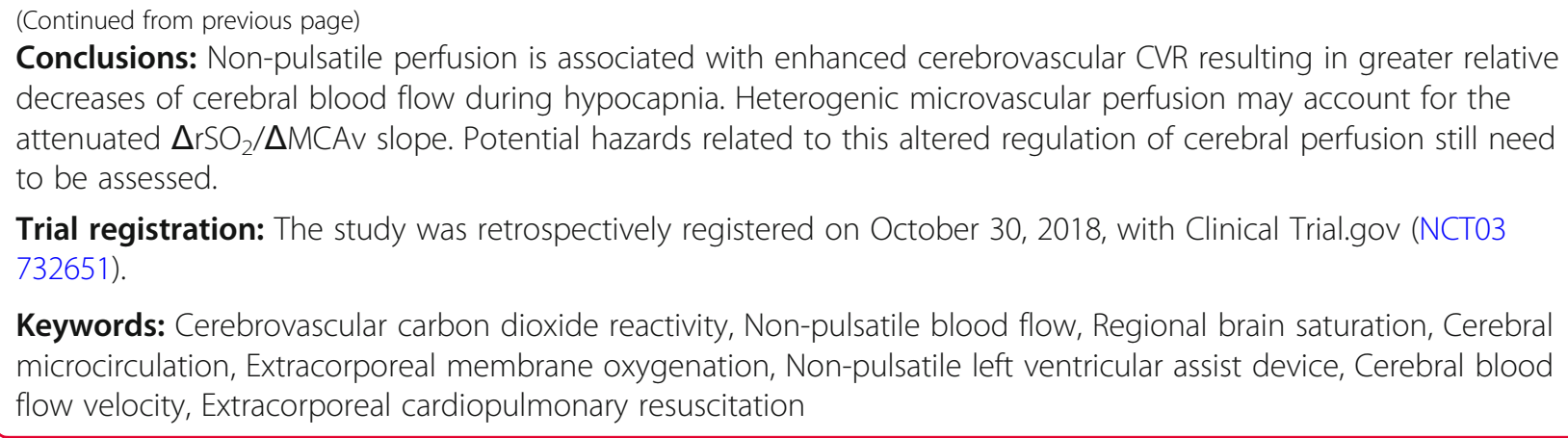

Keywords: Cerebrovascular carbon dioxide reactivity, Non-pulsatile blood flow, Regional brain saturation, Cerebral microcirculation, Extracorporeal membrane oxygenation, Non-pulsatile left ventricular assist device, Cerebral blood flow velocity, Extracorporeal cardiopulmonary resuscitation

\section{Background}

In the field of cardiac surgery and at many ICUs and emergency departments of tertiary care centres, it is daily practice to subject patients to a non-physiological condition where systemic blood flow either completely lacks pulsatility or pulsatility is greatly diminished [1]. Non-pulsatile flow, however, has been linked to increased vascular resistance, raised muscular sympathetic nervous activity, decreased oxygen consumption, endothelial dysfunction with loss of endothelial integrity and deterioration of microvascular perfusion. All of these factors supposedly contribute to increased incidences of gastrointestinal and intracerebral bleeding, strokes, and increased mortality on veno-arterial extracorporeal membrane oxygenation (VA-ECMO) [2-8].

In rats, endothelial-dependent vascular reactivity is dampened in less than 30 min on non-pulsatile cardiopulmonary bypass (CPB) [9]. Furthermore, within such a short period of absent pulsatility, heterogenous flow in human capillaries ensues. It is marked by vessels with absent being closely adjacent to those with very fast perfusion [2]. On the other hand, pulsatile blood flow is associated with improved cerebral microvascular circulation, a more homogenous tissue perfusion, an increased release of nitric oxide (NO) by the vascular endothelium and a higher ATP content in vital organs $[4,10]$. Pulsatile СРB flow proved to be advantageous after acute cerebral ischaemia in dogs, in the course of conventional heart surgery as well as in surgery requiring deep hypothermic cardiac arrest [11-13].

Neurological complications such as stroke, bleeding, cognitive dysfunction and delirium still remain a major concern in patients on mechanical circulatory support systems that provide complete non-pulsatile or minimal pulsatile flow (e.g. CPB, VA-ECMO) or continuous flow left ventricular assist devices (CF LVAD) [14-17]. Flowinduced tissue malperfusion, for example, could therefore potentially further augment ischaemia/reperfusion injury in patients in the course of extracorporeal cardiopulmonary resuscitation (ECPR) and loss of pulsatile cerebral perfusion might contribute to worse neurological outcome $[4,7,18]$. In fact, perfused vessel density, an established microcirculatory parameter, was negatively correlated with survival in patients requiring VA-ECMO due to cardiogenic shock [8].

There are a number of factors that determine cerebrovascular myogenic tone and consequently gross cerebral blood flow (CBF) and its local distribution. CBF is regulated by the metabolic demand of the brain, by cerebral perfusion pressure that underlies autoregulation, by the autonomic nervous system, and by hypoxaemia. Arterial partial pressure of carbon dioxide $\left(\mathrm{PaCO}_{2}\right)$ is another pivotal factor. The final effect of each of these CBF modulators results from the intricate interplay with other factors. For a detailed overview on this topic, we would like to refer the reader to recently published in-depth reviews $[19,20]$. In brief, changes in $\mathrm{PaCO}_{2}$ alter the diameter of cerebral arterioles by ways similar to those operative during changes of pulsatility thereby affecting nutritive blood flow through the capillary bed [10, 21]. Cerebrovascular $\mathrm{CO}_{2}$ reactivity (CVR) reflects this ability of the cerebral arterioles to modify $\mathrm{CBF}$ by dilating or constricting in response to changes in $\mathrm{PaCO}_{2}$ [22].

In instances when there is dual $\mathrm{CO}_{2}$ removal (e.g. via the oxygenator on partial cardiopulmonary bypass or ECMO as well as via the respirator), extremes in $\mathrm{PaCO}_{2}$ levels are not infrequent. Interestingly in this context, rapid decreases in $\mathrm{PaCO}_{2}$ immediately after onset of VA-ECMO treatment were significantly associated with intracerebral bleeds [23]. Although cerebral autoregulation is frequently severely compromised after cardiopulmonary resuscitation (CPR) [24], CVR is still intact and hypocapnia can easily set in especially when shock and therapeutic hypothermia have already diminished $\mathrm{CO}_{2}$ production. Hypocapnia post CPR, however, has been associated with poor neurological outcome, at least when it occurred within the first few hours after CPR, which unfortunately is not uncommon [25, 26].

We hypothesised that $\mathrm{CO}_{2}$-driven regulation of cerebral oxygenation during non-pulsatile blood flow is 
altered. Therefore, our objective was to compare the effect of non-physiological non-pulsatile blood flow on CVR and $\mathrm{rSO}_{2}$.

\section{Material and methods Study design and population}

The present investigation was a prospective case-control study. All procedures were approved by the Ethics Committee of the Medical University of Vienna (No. 117/ 2008) and were performed with written informed consent from study participants.

Thirty-two adult patients were enrolled in this study. One consenting patient had to be excluded because of an emergency intervention that became necessary prior to commencement of the study. Exclusion criteria were either symptomatic carotid artery disease or luminal narrowing of the carotid artery $>50 \%$ as well as the presence of soft plaques without symptoms, neurological pathologies (i.e. history of previous stroke or intracerebral bleeds, obstructive sleep apnea, obesity hypoventilation syndrome, prior meningitis or encephalitis, and multiple sclerosis), COPD with $\mathrm{CO}_{2}$ retention or other disturbances of the acid-base balance as well as women of childbearing age. Patients requiring preoperative diagnostic brain imaging studies with symptoms that could be associated with brain pathology were also excluded from the trial.

\section{Anaesthesia management}

All patients received $3.75-7.5 \mathrm{mg}$ midazolam orally $1 \mathrm{~h}$ preoperatively. Standard monitoring including a radial artery line was installed in the operating room together with neurological monitoring, i.e. the bispectral index (BIS, Medtronic, Minneapolis, MN, USA) and $\mathrm{rSO}_{2}$ determined by near infrared spectroscopy (INVOS 5100C, Covidien, Dublin, Ireland) using two optodes placed over the right and the left forehead, respectively. Monitoring began $10 \mathrm{~min}$ before the start of anaesthesia (baseline measurement). Anaesthesia was induced with $2 \mathrm{mg}$ midazolam, $0.2 \mu \mathrm{g} / \mathrm{kg}$ fentanyl and $1-2 \mathrm{mg} / \mathrm{kg}$ propofol. Cisatracurium $(0.2 \mathrm{mg} / \mathrm{kg})$ was given for tracheal intubation that was followed by placement of a central venous line. Furthermore, eight patients were additionally monitored with a pulmonary artery catheter.

Subsequently, the middle cerebral artery (MCA) was identified through the transtemporal window by duplex and Colour Doppler. Relative changes in blood flow velocity in this vessel (MCAv) determined by transcranial Doppler (TCD) frequently serve, despite its limitations, as a surrogate of relative changes in CBF [27]. The TCD transducers were screwed tight to a headset to prevent dislocation. Both the left and the right MCA were insonated, and measurements were taken using either both or (if one was distorted) the better signal. CVR $[\% / \mathrm{mmHg}]$ was calculated for hypo- and hypercapnia as:

$$
\begin{aligned}
\mathrm{CVR}= & {\left[\left(\mathrm{MCAv}_{\mathrm{h}}-\mathrm{MCAv}_{\mathrm{l}}\right) / \mathrm{MCAv}_{\mathrm{l}}\right] } \\
& \times 100 /\left(\mathrm{PaCO}_{2 \mathrm{~h}}-\mathrm{PaCO}_{2 \mathrm{l}}\right)
\end{aligned}
$$

whereby $h=$ value determined at the higher $\mathrm{PaCO}_{2}$ and $l=$ value determined at the lower $\mathrm{PaCO}_{2}$ level. The $\mathrm{MCAv} / \mathrm{PaCO}_{2}$ slope as a measure reflecting the degree of flow velocity changes following corresponding changes in $\mathrm{PaCO}_{2}$ was also calculated. In addition, the relationship between relative $\mathrm{CBF}$ changes and corresponding proportional shifts in $\mathrm{rSO}_{2}$ was determined.

Volume-controlled ventilation was employed before and after $\mathrm{CPB}$. The respective settings were as follows: $\mathrm{FiO}_{2}$ 0.3-0.4, tidal volume $7 \mathrm{~mL} / \mathrm{kg}$ body weight, respiratory rate $9 / \mathrm{min}$, and a PEEP level of 5 mmHg. Respiratory rate and $\mathrm{FiO}_{2}$ were adapted to achieve normoventilation and normoxia. Before going off CBP, the trachea was cleared from secretion and at least one vital capacity manoeuvre was performed. Cefazolin $(4 \mathrm{~g})$ was administered $30 \mathrm{~min}$ before skin incision and $2 \mathrm{~g}$ after termination of $\mathrm{CPB}$. Anaesthesia was maintained with 1-2 vol\% end-tidal sevoflurane and continuous administration of $200 \mu \mathrm{g} / \mathrm{h}$ fentanyl. BIS values between 40 and 50 were targeted and maintained. An initial dose of heparin (400 IU/ $\mathrm{kg}$ ) was administered before initiation of $\mathrm{CPB}$ to achieve an activated coagulation time $>400 \mathrm{~s}$. CPB was primed with $1 \mathrm{~L}$ Ringer's lactate, $500 \mathrm{~mL} 6 \%$ hydroxyethyl starch $130 / 0.4,100 \mathrm{~mL}$ mannitol $20 \%$ and 10.000 IE heparin. On CPB, mean arterial pressure (MAP) and haemoglobin levels were kept constant. At the end of $\mathrm{CPB}$, heparin was reversed by protamine at a 1:1 ratio of the total dose given immediately before $\mathrm{CPB}$.

\section{Intraoperative measurements (condition 1: non-pulsatile flow)}

In order to not delay surgery, we started with the nonpulsatile flow condition. During complete CPB after aortic cross-clamping sweep gas flow at the heart-lung machine was initially set to achieve a $\mathrm{PaCO}_{2}$ value of 40 $\mathrm{mmHg}$ (the $\mathrm{CO}_{2}$ tension can rapidly be determined by in-line measurement at the heart-lung machine after an initial calibration). Subsequently, $\mathrm{PaCO}_{2}$ was decreased and increased in a step-wise manner between 30, 40, and $50 \mathrm{mmHg}$. After a 5-min equilibration period, haemodynamic and metabolic variables were documented for every $\mathrm{PaCO}_{2}$ level. At the same time, $\mathrm{rSO}_{2}$ was recorded and mean MCAv was measured.

\section{Postoperative measurements (condition 2: pulsatile blood flow)}

Postoperative measurements were performed after ICU admission during stable conditions. Patients received propofol (average dose: $3 \mathrm{mg} / \mathrm{kg} / \mathrm{h}$ ) and remifentanil 
$(0.1 \mu \mathrm{g} / \mathrm{kg} / \mathrm{min})$ to achieve the same BIS values as intraoperatively to ensure a comparable cerebral metabolic rate of oxygen [28]. Volume-controlled ventilation was continued with the abovementioned settings. Minute volume was adapted according to blood gas analysis to reach the desired $\mathrm{PaCO}_{2}$ level in the same sequence as on $\mathrm{CPB}$ by changing respiratory rate but not tidal volume to avoid concomitant changes in intrathoracic pressure during measurements while we simultaneously tried to maintain sedation, patient positioning, blood pressure, cardiac output and body temperature.

\section{Statistical analysis}

Statistical analysis was performed using Stata/IC 15.1 (StataCorp LLC) and GraphPad Prism 5.04 software (GraphPad Software). Categorical data was reported as count (percentage), normally distributed continuous data as mean ( \pm standard deviation) and non-normally distributed data as median (interquartile range).

The effect of pulsatile and non-pulsatile blood flow on CVR was analysed using multilevel mixed-effects linear regression for repeated measures followed by post hoc Tukey test (xtmixed Stata). A Pearson's productmoment correlation was utilised to assess the relationship between $\Delta \mathrm{rSO}_{2}$ and $\triangle \mathrm{MCAv}$. A paired $t$-test was performed to analyse differences in MAP, BIS and haemoglobin between both blood flow modalities (nonpulsatile vs. pulsatile). $p$ values $<0.05$ were considered significant.

\section{Results}

Patient characteristics and type of surgery is depicted in Table 1. For each condition (i.e. pulsatile or nonpulsatile flow), MAP, haemoglobin, BIS, and body temperature did not change over the measurement period. MAP and BIS values, however, were significantly lower on $\mathrm{CPB}$ ( $63 \pm 8$ vs. $73 \pm 10 \mathrm{mmHg}$ and $40 \pm 6$ vs. $48 \pm 7, p<0.0001)$ while $\mathrm{PaO}_{2}$ was significantly higher (175 \pm 56 vs. $135 \pm 32 \mathrm{mmHg}, p<0.05)$. Isovolaemic haemodilution resulted in a decreased haemoglobin level on CPB $(8.4 \pm 1.1 \mathrm{~g} / \mathrm{dL}$ vs. $11.1 \pm 1.1 \mathrm{~g} / \mathrm{dL}, p<0.0001)$. Irrespective of flow mode, we neither observed increases in MAP during hypercapnia (Table 2) nor instances of hypoxaemia.

Absolute values of $\mathrm{rSO}_{2}$, arterial haemoglobin oxygen saturation, $\mathrm{PaO}_{2}$, patient temperature, MAP, and, where available, intra- and postoperatively determined cardiac indeces after $\mathrm{CO}_{2}$ step changes during non-pulsatile and pulsatile flow are listed in Table 2. The course of absolute MCAv during alterations of $\mathrm{PaCO}_{2}$ within each flow mode is depicted in Fig. 1. MCAv was significantly lower during hypocapnia compared to normocapnia $(p<0.0001)$, while MCAv was significantly higher during hypercapnia compared to normocapnia $(p<0.0001)$. There was also a
Table 1 Patient characteristics and perioperative data

\begin{tabular}{|c|c|}
\hline Gender male/female ratio $n(\%)$ & $23 / 8(74 / 26)$ \\
\hline Age (years) mean $\pm S D$ & $65 \pm 8$ \\
\hline Arterial hypertension $n(\%)$ & $23(74)$ \\
\hline Chronic obstructive lung disease $n(\%)$ & $4(12)$ \\
\hline Diabetes $n(\%)$ & $5(16)$ \\
\hline Current smoker $n(\%)$ & $10(32)$ \\
\hline \multicolumn{2}{|l|}{ Left ventricular ejection fraction $n(\%)$} \\
\hline$>50 \%$ & $21(67)$ \\
\hline $40-50 \%$ & $4(12)$ \\
\hline$<40 \%$ & $7(22)$ \\
\hline Height $(\mathrm{cm})$ mean \pm SD & $172 \pm 9$ \\
\hline Bodyweight $(\mathrm{kg})$ mean $\pm \mathrm{SD}$ & $82 \pm 16$ \\
\hline Body mass index $\left(\mathrm{kg} / \mathrm{m}^{2}\right)$ mean $\pm \mathrm{SD}$ & $28 \pm 5$ \\
\hline No antiplatelet therapy $n(\%)$ & $16(51)$ \\
\hline Single antiplatelet therapy $n(\%)$ & $11(35)$ \\
\hline Dual antiplatelet therapy $n(\%)$ & $5(16)$ \\
\hline \multicolumn{2}{|l|}{ Surgical procedure $n(\%)$} \\
\hline CABG only & $10(32)$ \\
\hline CABG with aortic valve replacement/repair & $7(22)$ \\
\hline CABG with mitral valve replacement/repair & $7(22)$ \\
\hline Aortic valve replacement & $7(22)$ \\
\hline \multicolumn{2}{|l|}{ Vasoactive agents } \\
\hline Dobutamine $n(\%)$ & $11(35)$ \\
\hline Noradrenaline $n(\%)$ & $31(100)$ \\
\hline Levosimendan $n(\%)$ & $5(16)$ \\
\hline \multicolumn{2}{|l|}{ Blood and coagulation products } \\
\hline Packed red blood cells $n$ (\%) & $13(41)$ \\
\hline Fibrinogen $n(\%)$ & $11(35)$ \\
\hline Tranexamic acid $n(\%)$ & $31(100)$ \\
\hline Tranexamic acid (g) mean \pm SD & $2.5 \pm 1.0$ \\
\hline Cardiopulmonary bypass time $(\mathrm{min})$ mean \pm SD & $148 \pm 75$ \\
\hline Aortic cross-clamping time (min) mean $\pm S D$ & $93 \pm 48$ \\
\hline Mild hypothermia $n(\%)$ & $9(29)$ \\
\hline Highest serum lactate level $(\mathrm{mg} / \mathrm{dL})$ mean $\pm \mathrm{SD}$ & $2.7 \pm 2$ \\
\hline
\end{tabular}

$S D$ standard deviation, $n$ number of patients, $C A B G$ coronary artery bypass graft

Data are either presented as absolute numbers (percentage) or as means \pm SD

statistically significant difference between flow modes $(p<$ 0.033). Relative MCAv changes of individual patients clearly show that greater shifts from normocapnia occurred when flow was non-pulsatile (Fig. 2, $p<0.05$ ). The $\mathrm{MCAv} / \mathrm{PaCO}_{2}$ slope was $14.4 \mathrm{~cm} / \mathrm{s} / \mathrm{mmHg}$ [CI 11.8-16.9], during non-pulsatile and $10.4 \mathrm{~cm} / \mathrm{s} / \mathrm{mmHg}$ [CI 7.9-13.0] during pulsatile blood flow $(p=0.032)$.

Under hypocapnia and non-pulsatile flow, CVR was significantly increased $(4.3 \pm 1.7 \% / \mathrm{mmHg})$ compared to pulsatile flow $(3.1 \pm 1.3 \% / \mathrm{mmHg}, p=0.017)$. During hypercapnia, 
Table 2 Oxygenation, patient temperature and haemodynamics at the time of measurement

\begin{tabular}{|c|c|c|c|c|c|c|}
\hline Flow mode $\mathrm{PaCO}_{2}$ level & $\mathrm{rSO}_{2}(\%)$ & $\mathrm{SaO}_{2}(\%)$ & $\mathrm{PaO}_{2}(\mathrm{mmHg})$ & Temp $\left({ }^{\circ} \mathrm{C}\right)$ & MAP $(\mathrm{mmHg})$ & $\mathrm{Cl}\left(\mathrm{L} / \mathrm{min} / \mathrm{m}^{2}\right)$ \\
\hline \multicolumn{7}{|l|}{ Non-pulsatile } \\
\hline $30 \mathrm{mmHg}$ & $56[51-60]$ & 99 [98-100] & 160 [140-177] & $36.3[35.9-36.7]$ & 63 [57-68] & $2.5[2.4-2.7]$ \\
\hline $40 \mathrm{mmHg}$ & 59 [57-63] & 99 [98-100] & 170 [154-197] & $36.4[35.8-36.7]$ & $63[57-69]$ & $2.5[2.4-2.7]$ \\
\hline $50 \mathrm{mmHg}$ & $62[57-66]$ & 99 [98-100] & 161 [133-190] & 36.4 [35.9-36.7] & $63[54-68]$ & $2.5[2.3-2.7]$ \\
\hline \multicolumn{7}{|l|}{ Pulsatile } \\
\hline $30 \mathrm{mmHg}$ & $58[56-64]$ & $100^{*}[99-100]$ & $137^{*}[116-161]$ & $36.5[36.3-36.7]$ & $71^{*}[66-80]$ & $2.7[2.1-3.3]$ \\
\hline $40 \mathrm{mmHg}$ & $61[59-67]$ & $100^{*}[100-100]$ & $140 *$ [109-164] & $36.4[36.3-36.7]$ & $72^{*}[65-83]$ & $2.6[1.9-2.8]$ \\
\hline $50 \mathrm{mmHg}$ & $64[62-70]$ & $100^{*}[99-100]$ & $120^{*}[101-146]$ & $36.5[36.3-36.7]$ & $68^{*}[65-75]$ & $2.6[2.0-3.3]$ \\
\hline
\end{tabular}

Values are medians [25th-75th percentile], $\mathrm{rSO}_{2}$ Regional brain saturation, $\mathrm{SaO}_{2}$ Arterial haemoglobin oxygen saturation, $\mathrm{PaO}{ }_{2}$ Arterial partial pressure of oxygen, Temp patient temperature MAP mean arterial blood pressure, $\mathrm{Cl}$ cardiac index $(n=8),{ }^{*}=p<0.05$ vs. corresponding value during non-pulsatile flow (ANOVA with post hoc Tukey test)

however, non-pulsatile CVR was only nominally but not statistically greater in relation to pulsatile CVR $(3.5 \pm 1.8 \%$ / mmHg vs. $2.6 \pm 1.2 \% / \mathrm{mmHg}, p=0.197$, Fig. 3 ).

Independent of the flow mode, we saw a decline in $\mathrm{rSO}_{2}$ during hypocapnia and a corresponding rise during hypercapnia $(p<0.0001)$. However, despite more pronounced $\mathrm{CO}_{2}$-driven flow velocity changes during nonpulsatile flow, there was no equivalent difference in $\Delta \mathrm{rSO}_{2}$ between corresponding $\mathrm{PaCO} 2$ levels when compared to pulsatile flow. The $\mathrm{rSO}_{2} / \mathrm{PaCO}_{2}$ slope was $2.8 \% / \mathrm{mmHg}$ [CI $1.5-4.0$ ] on $\mathrm{CPB}$ and $3.1 \% / \mathrm{mmHg}$ [CI $1.9-4.3]$, postoperatively $(p=0.72)$. As shown in Fig. 4, $\triangle \mathrm{MCAv}$ and $\triangle \mathrm{rSO}_{2}$ changes were closely related to each other during non-pulsatile $(r=0.724, p<0.001)$ and pulsatile blood flow $(r=0.796, p<0.001)$. However, during non-pulsatile flow, the slope of the regression line was less steep and cerebral CVR more accentuated as compared to pulsatile perfusion.

\section{Discussion}

In the present study, short-term non-pulsatile perfusion was associated with significantly enhanced cerebrovascular
CVR compared to pulsatile blood flow resulting in exaggerated responses in CBF when non-physiologically low $\mathrm{PaCO}_{2}$ values were reached. These changes in CBF, however, were not accompanied by equivalent changes in $\mathrm{rSO}_{2}$.

Instances of hypocapnia are not infrequent in low cardiac output and INTERMACS 1 or 2 patients on extracorporeal assist devices with or without dual $\mathrm{CO}_{2}$ removal (e.g. VA-ECMO, extracorporeal cardiopulmonary resuscitation (ECPR) or CF LVAD) as well as after conventional CPR [26]. They have mostly been associated with poor neurological outcome. Prolonged intraoperative hypocapnia by itself has recently also been associated with postoperative delirium in non-cardiac surgery [29]. Our observations indicate that the effect of hypocapnia-induced cerebral vasoconstriction may even be more extensive in the presence of non-pulsatile cerebral blood flow. In contrast, the impact of hypercapnia on vasodilation was not significantly different from that seen under pulsatile flow conditions in the current study.

To guarantee propagation of pulsatility into the cerebral circulation, we compared CVR during non-pulsatile

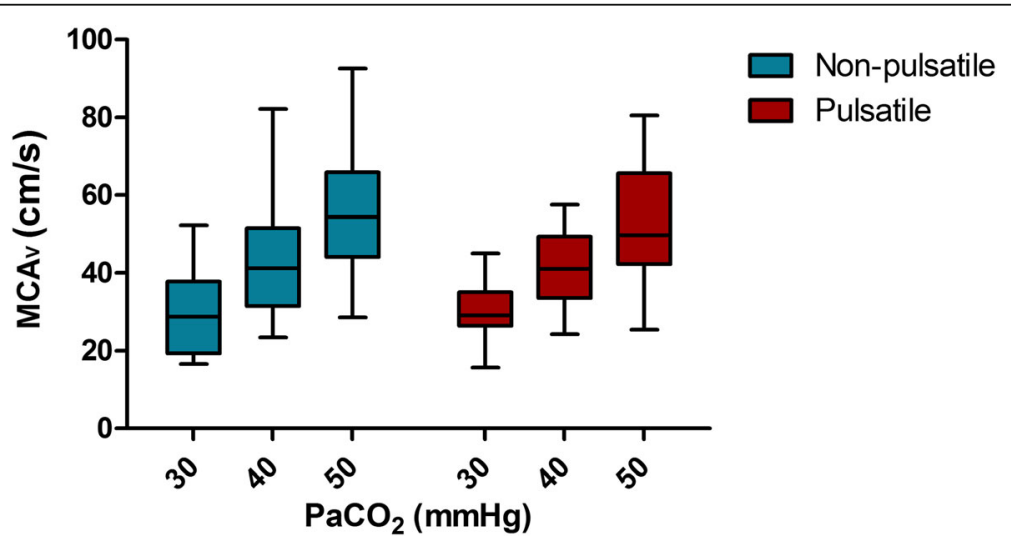

Fig. 1 Absolute MCAv measures determined during non-pulsatile and pulsatile flow at hypo-, normo-, and hypercapnia MCAv blood flow velocity in the middle cerebral artery 


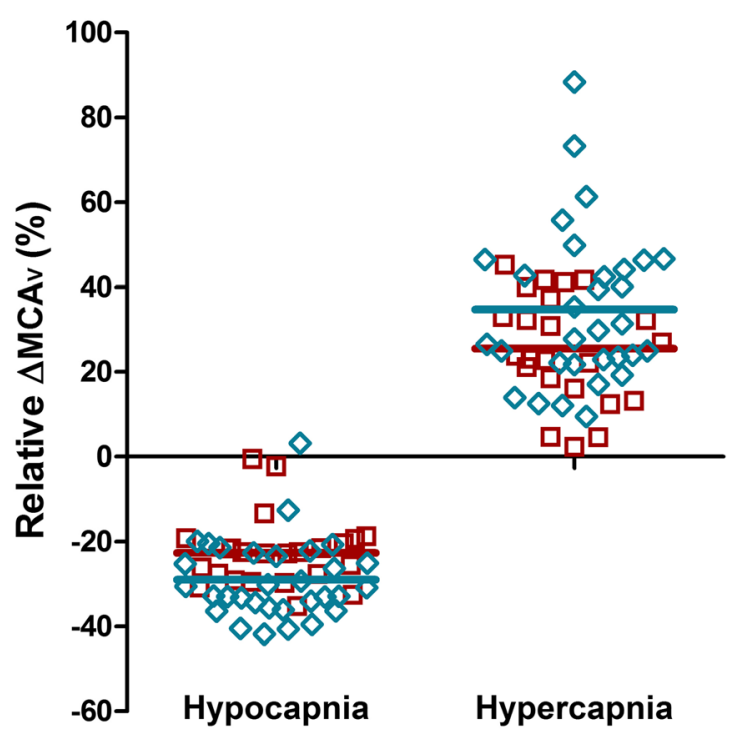

$\diamond$ Non-pulsatile

口 Pulsatile

middle cerebral artery

blood flow on complete $\mathrm{CPB}$ with the same patient's CVR postoperatively on the ICU during pulsatile blood flow generated by the beating heart itself. In previous studies investigating induced pulsatile flow on $\mathrm{CPB}$, it has never been ruled out that it was simply blunted pulsatility (i.e. with reduced systolic and pulse pressures) that was created, which lacks excess energy [30]. Moreover, even in the paediatric population, not all available pulsatile pumps generate this higher haemodynamic energy when compared with non-pulsatile pumps [31]. Mitigated pulsatility, however, which is frequently observed in ECMO patients early after implant, appears to be similar to non-pulsatile flow as it also increases muscular sympathetic nerve activity [32]. Furthermore, long duration of diastole and low levels of diastolic pressure elicited sympathetic bursts in CF LVAD as well as in VA-ECMO patients with minimal pulsatility [32]. Interestingly in this context, $2 \mathrm{~h}$ after exposure to VAECMO with a high flow rate $(120-150 \mathrm{~mL} / \mathrm{kg} / \mathrm{min})$, decreased NO production was noted in cerebral arteries of lambs indicating impaired cerebral vascular endothelial function [33]. This phenomenon likely contributes to

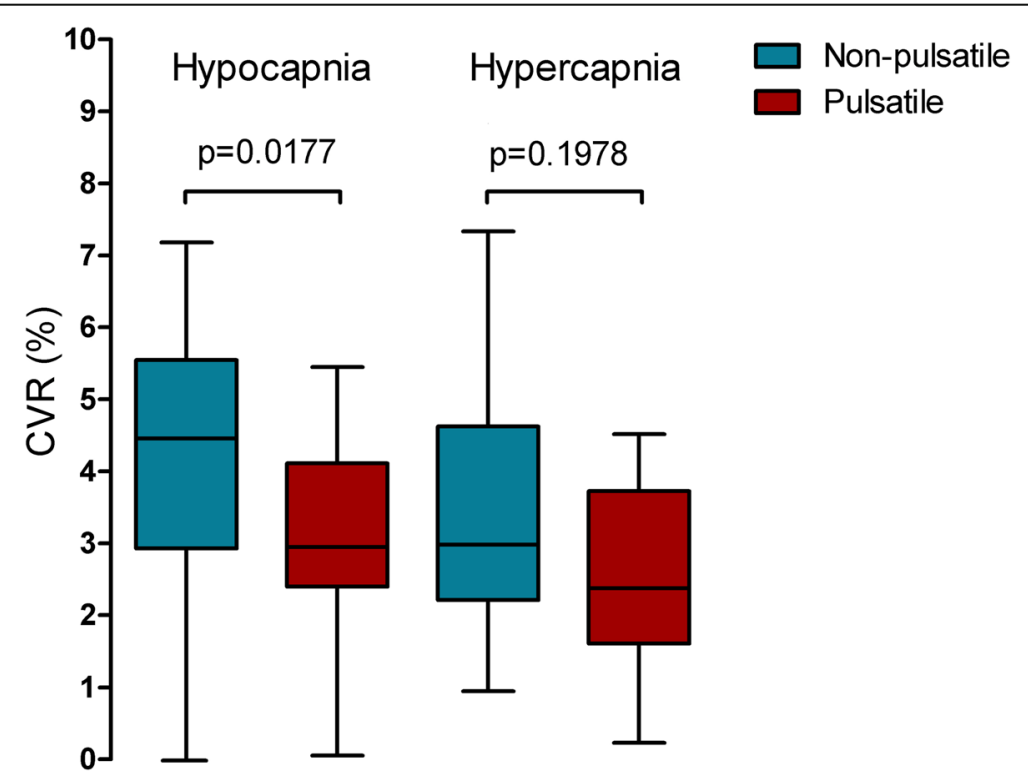

Fig. 3 Cerebrovascular $\mathrm{CO}_{2}$ reactivity during hypo- and hypercapnia and pulsatile as well as non-pulsatile blood flow CVR cerebrovascular $\mathrm{CO}_{2}$ reactivity 


\section{Non-pulsatile flow}

$r=0.7244, p<0.0001$

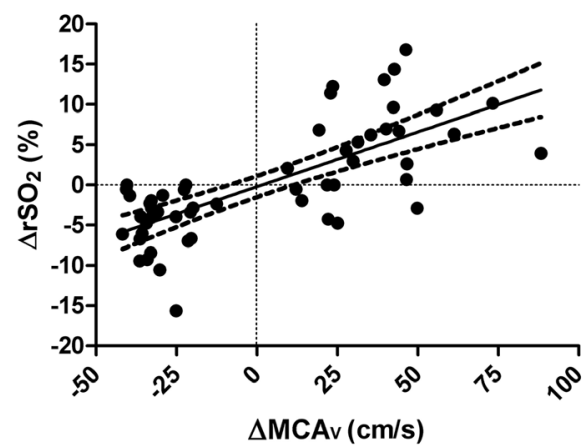

Pulsatile flow

$r=0.7962, p<0.0001$

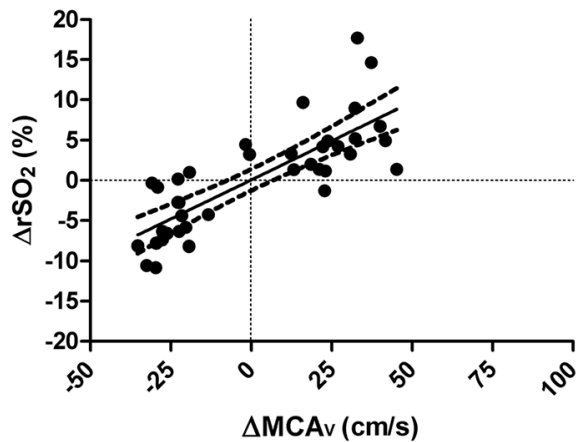

Fig. 4 Correlation of $\triangle M C A v$ and $\Delta \mathrm{rSO}_{2}$. $r$ correlation coefficient, $\triangle M C A v$ relative change in blood flow velocity in the middle cerebral artery, $\Delta \mathrm{rO}_{2}$ relative change in regional cerebral oxygen saturation

capillary collapse and shunting when a critical closing pressure cannot be reached whereby the driving pressure is usually created by the excess energy generated through the ejection of blood from the left ventricle into the aorta [30]. O'Neil and co-workers studied sublingual microcirculation on $\mathrm{CPB}$, yet without specifically looking into $\mathrm{PaCO}_{2}$-generated vasoreactivity and found that the proportion of normally perfused microvessels decreases immediately with onset of non-pulsatile flow [2]. In a similar study in 20 patients undergoing cardiac surgery, the same researchers reported an increase in vessels with hyperdynamic flow when blood flow was non-pulsatile, which may represent capillary shunting [5]. These results could account for our observation that despite greater $\triangle \mathrm{MCAv}$ during non-pulsatile flow, $\Delta \mathrm{rSO}_{2}$ did not change proportionally although a close relationship still persisted. Conversely, this also implies that potential benefits of pulsatile flow related to improved microcirculatory perfusion may not be traceable by higher $\mathrm{rSO}_{2}$ values [34]. The dependence of brain tissue saturation on $\mathrm{PCO}_{2}$ has previously been confirmed in healthy individuals and patients undergoing cardiac surgery [35]. In addition, during carotid endarterectomy, $\mathrm{rSO}_{2}$ closely correlated with MCAv during cross clamping of the ipsilateral common carotid artery [36]. These findings are in line with our results as $\mathrm{rSO}_{2}$ and $\mathrm{PaCO}_{2}$ changed in the same direction. $\mathrm{rSO}_{2}$ further changed in parallel to MCAv. However, there appears to be some uncoupling during non-pulsatile flow with enhanced reductions in cerebral blood flow during hypocapnia.

Findings from previous studies in this area can barely be compared with our results since investigations were then usually conducted with only few patients assigned to either of the two flow modes, during moderate hypothermic $\mathrm{CPB}$, with different anaesthetics (e.g. $\mathrm{N}_{2} \mathrm{O}$ ), and partly at very low cerebral perfusion pressures [37]. In our trial, the 31 patients served as their own controls and only few patients were operated under mild hypothermia. In addition, several studies have shown that CVR is maintained with both anaesthetics we employed when given within normal clinical ranges [38] as was the case here, despite the fact that anaesthesia likely compromises basal vascular tone [39]. In this trial, end-tidal sevoflurane concentrations ranging between 0.3 and 1.5 MAC (mean dose 0.8 MAC) was administered intra- and low-dose propofol (median 2.5 [range $1.8-3.9] \mathrm{mg} / \mathrm{kg} / \mathrm{h}$ ) postoperatively.

Although changes in $\mathrm{PaCO}_{2}$ alter the diameter of cerebral arterioles and thus determine nutritive microcirculatory blood flow through the capillary bed, the large cerebral arteries are frequently considered to be noncompliant serving as a conduit to distribute and store blood volume [27]. In young, healthy, and spontaneously breathing volunteers, however, luminal changes of up to $10 \%$ have been calculated during hypo- and hypercapnia when $\Delta \mathrm{PetCO}_{2}$ exceeded $10 \mathrm{mmHg}$ [40]. It is unclear if similar changes also occur in sick, anaesthetised and ventilated patients undergoing cardiac surgery. As we did not measure the diameter of the interrogated vessel, we cannot rule out that variations in the vessel calibre impacted on the measured MCAv whereby particularly MCAv values during hypercapnia would be affected. The modest hyperoxia during non-pulsatile flow on $\mathrm{CPB}$ should rather decrease the slope of the curve describing the relationship between $\mathrm{PaCO}_{2}$ and MCAv, which would be just the opposite we found [41]. As mentioned above, sevoflurane anaesthesia that we used on $\mathrm{CPB}$ has been demonstrated to preserve CVR $(4.1 \pm 0.7 \% / \mathrm{mmHg}$ $\left.\mathrm{PaCO}_{2}\right)$ as well as MCAv in healthy patients undergoing orthopaedic surgery when MAP was kept at $80 \mathrm{mmHg}$ with phenylephrine [42]. MAP in our patients was generally $<80 \mathrm{mmHg}$ and showed minor though statistically significant differences between pulsatile and nonpulsatile flow. In this regard, it should, however, be kept 
in mind that current research confirmed interactions between CVR and cerebrovascular autoregulation, primarily affecting the upper threshold [43, 44]. Nevertheless, MAPs we recorded were all within the critical $\mathrm{PaCO}_{2}$ dependent autoregulatory thresholds that have been reported during anaesthesia [37, 45]. In our trial, cerebral perfusion pressures thus should not have had an effect on the measured MCAv. Neither during non-pulsatile nor during pulsatile flow did we observe rises in MAP accompanying periods of hypercapnia. A potential explanation may be the suppression of sympathetic activity during anaesthesia. Interestingly in this context, as CVR is also mitigated during sympathetic blockade [46, 47], increased sympathetic activity in turn, which has been confirmed during non-pulsatile blood flow [48], might augment CVR, which is exactly what we have seen. It is, therefore, probably not pulsation per se that accounts for the observed changes in the $\mathrm{PaCO}_{2}$-dependent regulation of cerebral artery myogenic tone [44] but secondary effects induced by pulsatile blood flow like for example eNOs activity and coupling $[49,50]$ or modulations of the autonomic nervous system output [51]. Furthermore, a reduced myogenic tone has been observed in isolated murine cerebral arteries when subjected to static pressure, which may also account for the accentuated CVR we determined [50].

\section{Limitations}

This trial still does have some limitations primarily related to the chosen protocol. Use of CPB always causes some degree of isovolaemic haemodilution that may impact blood viscosity and eventually microcirculatory perfusion. Haemodilution might thereby affect the magnitude of CVR. Data from the literature, however, is inconclusive. At haematocrits $<28 \%$, both attenuated and enhanced CVR has been reported in patients undergoing heart surgery during hypocapnia, while no alteration was seen during hypercapnia [52, 53]. However, isovolaemic haemodilution by low-molecular-weight dextran infusion, for example, did not increase but instead decreased acetazolamide-induced cerebral vasoreactivity [54]. In addition, CBF is augmented when arterial oxygen content drops, which, however, should only have a marginal effect considering the actual haemoglobin levels in our patients during and after surgery [55]. Nevertheless, the enhanced CVR we observed under non-pulsatile flow may be related to some extent to the lower haematocrits on CPB.

Another issue that needs to be addressed is the different types of anaesthetics that were employed here as their impact on the BIS level, CBF, and $\mathrm{CMRO}_{2}$ may not be the same. Sevoflurane was administered intraoperatively due to its ascribed cardioprotective properties but could not be continued into the postoperative period as we lack the technology that allows its administration in the ICU. Data from eight young and healthy volunteers indicate that 1.5 vol\% sevoflurane reduces regional CBF less than propofol (propofol plasma concentration ranged between 2.6 and $4.6 \mu \mathrm{g} / \mathrm{mL}$ ) whereby $\mathrm{CMRO}_{2}$ was equally decreased and MAP and BIS depressed to a similar degree [56]. In relation, the propofol dose our patients received was much less due to the concomitant administration of remifentanil, which may explain the greater neuronal activity in the frontal cortex evidenced by higher BIS levels postoperatively. Therefore, one should not expect to find a significant propofol-induced depression of global CBF although we cannot comment on the eventual regional distribution of CBF. In this context, alterations in the cortical CBF/ $\mathrm{CMRO}_{2}$ ratio have only been observed at higher propofol concentrations (i.e. $7.8 \pm 2.1 \mathrm{mg} / \mathrm{kg} / \mathrm{h}$ ) that were also accompanied by a BIS level as low as 20 , which makes it unlikely that propofol in this study affected postoperative $\mathrm{rSO}_{2}$ [57]. As a matter of fact, mean MCAv under $6 \mathrm{mg} /$ $\mathrm{kg} / \mathrm{h}$ propofol anaesthesia (a higher dose than we employed) observed in ASA 1 patients was by trend somewhat higher but comparable with MCAv of our patients in the ICU (41-49-58 cm/s for hypo-, normo-, and hypercapnia). In addition, relative CVR was preserved in this investigation [58]. In comparison, equivalent MCAv measured again in young and healthy ASA 1 patients, however, under 1.2 and 1.5 MAC sevoflurane anaesthesia were $25 / 33-47 / 55-76 / 78 \mathrm{~cm} / \mathrm{s}[59,60]$, which are strikingly similar to those obtained in a spontaneously breathing non-anaesthetized young volunteer $(30-50-70 \mathrm{~cm} / \mathrm{s})$ [41]. Obviously, mean absolute MCAv can vary to some extent. Hence, relative CVR seems to be a more appropriate indicator of the effect of $\mathrm{PaCO}_{2}$ alterations on $\mathrm{CBF}$ as absolute measures.

Despite the mentioned drawbacks of our protocol, it does have advantages, too. Because we did not compare different groups of patients subjected to different flow modes, we could reduce differences in $\triangle M C A v$ resulting from other potential confounders (e.g. diabetes mellitus, arterial hypertension, age, atherosclerosis of the cerebral vessels, previously unrecognised anatomical abnormalities). Furthermore, it seems improbable that CVR was affected by mild hypothermia with $\alpha$-stat $\mathrm{pH}$ management that was instituted in few patients on CPB [52]. Moreover, none of the patients had developed a fever when the second measurement was carried out in the ICU. Additionally, catecholamines as well as levosimendan were administered at low dosages that should not affect CVR under anaesthesia to a meaningful extent $[61,62]$. They were frequently already started intraoperatively and continued after surgery.

\section{Conclusion}

In conclusion, in older anaesthetized cardiac surgery patients, non-pulsatile blood flow caused enhanced CVR. If, 
however, unphysiological $\mathrm{PaCO}_{2}$ values in conjunction with this flow mode actually increase the odds of undesired cerebral complications, as it was the case after traumatic brain injury, requires further investigations [63]. Especially with a leftward-shifted oxygen-haemoglobin dissociation curve and a heterogenous microvascular perfusion, $\mathrm{rSO}_{2}$ recordings may additionally overestimate true brain tissue oxygenation during hypocapnia when CBF becomes non-pulsatile. This would further diminish the prognostic value of $\mathrm{rSO}_{2}$ post ECPR regarding neurological outcome [64].

As even short-term non-pulsatile flow conditions rapidly affect the cerebral circulation, these findings could be especially relevant in patients requiring extracorporeal mechanical assist devices that do generate either no or merely blunted pulsatile brain perfusion. Patients with low left ventricular ejection fraction receiving emergent VA-ECMO and depicting low-pulsatile systemic perfusion could potentially be particularly vulnerable regarding cerebral insults during hypothermic and hypocapnic states $[3,65,66]$. The currently poor neurological outcome after cardiac arrest with or without ECPR is often clinically initiated by convulsions and myoclonus. In this context, hypocapnia-induced vasoconstriction leading to tissue alkalosis and hypoxaemia might also play a certain role in the elicitation of seizures in susceptible patients immediately after global brain ischaemia [67-69].

\section{Abbreviations \\ BIS: Bispectral index; CBF: Cerebral blood flow; CF LVAD: Continuous flow left ventricular assist device; COPD: Chronic obstructive pulmonary disease; CVR: Carbon dioxide reactivity; CPB: Cardiopulmonary bypass; \\ CPR: Cardiopulmonary resuscitation; ECMO: Extracorporeal membrane oxygenation; ECPR: Extracorporeal cardiopulmonary resuscitation; ICU: Intensive care unit; MAP: Mean arterial pressure; MCA: Middle cerebral artery; $\mathrm{PaCO}_{2}$ : Arterial partial pressure of oxygen; PEEP: Positive end- expiratory pressure; $\mathrm{rSO}_{2}$ : Regional brain tissue saturation; TCD: Transcranial Doppler; VA-ECMO: Veno-arterial extracorporeal membrane oxygenation; MCAv: Blood flow velocity determined in the middle cerebral artery}

\section{Acknowledgements}

This study was supported by the Division of Cardiothoracic and Vascular Anaesthesia and Intensive Care Medicine at the General Hospital Vienna, Austria.

\section{Take-home message}

Non-pulsatile systemic blood flow generated by extracorporeal assist devices enhances cerebral $\mathrm{CO}_{2}$ reactivity in anaesthetised cardiac surgery patients. In addition, there is a weaker relationship between regional cerebral saturation and cerebral blood flow.

\section{Tweet}

Loss of pulsatile blood flow affects cerebral blood flow regulation by carbon dioxide and brain tissue saturation.

\section{Authors' contributions}

$E P$ and $M D$ conceived the study protocol, contributed to the interpretation of the data and helped revise the manuscript. HR, KK and KSD participated in the design of the study, included all the patients, performed the measurements, collected the data and helped interpreting them. CMV, AF, MM, JM and HJA analysed the data, helped in writing the manuscript as well as in interpreting the data. All authors read and approved the final manuscript.

\section{Funding}

No funding was received for this study.

\section{Availability of data and materials}

The datasets used and/or analysed during the current study are available from the corresponding author on reasonable request.

\section{Ethics approval and consent to participate}

The study protocol was approved by the local Ethics Committee and informed consent was obtained from the patients.

\section{Consent for publication}

Consent for publication was obtained by the patients.

\section{Competing interests}

The authors declare that they have no competing interests.

\section{Author details}

'Division of Cardiothoracic and Vascular Anaesthesia and Intensive Care Medicine, Department of Anaesthesia, Intensive Care Medicine, and Pain Medicine, Vienna General Hospital, Medical University of Vienna, Waehringer Guertel 18-20, 1090 Vienna, Austria. ${ }^{2}$ Department of Anaesthesia and Intensive Care Medicine, LKH Feldkirch, Feldkirch, Austria. ${ }^{3}$ Department of Anaesthesia, Intensive Care Medicine and Pain Medicine, Klinikum Traunstein, Traunstein, Germany. ${ }^{4}$ Department of Neurology, Vienna General Hospital, Medical University of Vienna, Vienna, Austria. ${ }^{5}$ Division of Thoracic Surgery, Department of Surgery, Vienna General Hospital, Medical University of Vienna, Vienna, Austria.

Received: 6 August 2019 Accepted: 13 November 2019

Published online: 30 December 2019

\section{References}

1. Purohit SN, Cornwell WK, Pal JD, Lindenfeld J, Ambardekar AV. Living without a pulse: the vascular implications of continuous-flow left ventricular assist devices. Circ Heart Fail. 2018;11:a004670.

2. O'Neil MP, Fleming JC, Badhwar A, Guo LR. Pulsatile versus nonpulsatile flow during cardiopulmonary bypass: microcirculatory and systemic effects. Ann Thorac Surg. 2012;94:2046-53.

3. Inamori S, Shirai M, Yahagi N, et al. A comparative study of cerebral microcirculation during pulsatile and nonpulsatile selective cerebral perfusion: assessment by synchroton radiation microangiography. ASAIO J. 2013;59:374-9.

4. Salameh A, Kühne L, Grassl M, et al. Protective effects of pulsatile flow during cardiopulmonary bypass. Ann Thorac Surg. 2015;99:192-9.

5. O'Neil MP, Alie R, Guo LR, Myers ML, Murkin J, Ellis C. Microvascular responsiveness to pulsatile and non-pulsatile flow during cardiopulmonary bypass. Ann Thorac Surg. 2018;105:1745-53.

6. Stöhr EJ, McDonnell BJ, Colombo PC, Willey JZ. CrossTalk proposal: blood flow pulsatility in left ventricular assist device patients is essential to maintain normal brain physiology. J Physiol. 2019;597:353-6.

7. Wadowski PP, Steinlechner B, Zimpfer D, et al. Functional capillary impairment in patients with ventricular assist devices. Sci Rep. 2019;9:5909.

8. Kara A, Akin S, dos Reis Miranda D, et al. Microcirculatory assessement of patients under VA-ECMO. Crit Care. 2016;20:344

9. Modine T, Azzaoui R, Ouk T, et al. Changes in cerebral vascular reactivity occur early during cardiopulmonary bypass in the rat. Ann Thorac Surg. 2006;82:672-8.

10. Brian JE Jr, Faraci FM, Heistad DD. Recent insights into the regulation of cerebral circulation. Clin Exp Pharmacol Physiol. 1996;23:449-57.

11. Tranmer BI, Gross CE, Kindt GW, Adey GR. Pulsatile versus nonpulsatile blood flow in the treatment of acute cerebral ischemia. Neurosurgery. 1986; 19:724-31.

12. Murkin JM, Adams SJ, Novick RJ, et al. Monitoring brain oxygen saturation during coronary bypass surgery: a randomized, prospective study. Anesth Analg. 2007;104:51-8.

13. Singal RK, Docking $L M$, Girling $L G$, et al. Biologically variable bypass reduces enzymuria after deep hypothermic circulatory arrest. Ann Thorac Surg. 2006; 82:1480-8.

14. Roach GW, Kanchuger M, Mangano CM, et al. Adverse cerebral outcome after coronary bypass surgery. N Engl J Med. 1996;335:1857-63. 
15. Acharya D, Loyaga-Rendon R, Morgan CJ, et al. INTERMACS analysis of stroke during support with continuous-flow left ventricular assist devices. JACC Heart Fail. 2017;5:703-11.

16. Fendler TJ, Spertus JA, Gosch KL, et al. Incidence and predictors of cognitive decline in patients with left ventricular assist devices. Circ Cardiovasc Qual Outcomes. 2015;8:285-91.

17. Caro MA, Rosenthal JL, Kendall K, Pozuelo L, Funk MC. What the psychiatrist needs to know about ventricular assist devices: a comprehensive review. Psychosomatics. 2016;57:229-37.

18. Selnes OA, Gottesman RF, Grega MA, Baumgartner WA, Zeger SL, McKhann GM. Cognitive and neurologic outcomes after coronary-artery bypass surgery. N Engl J Med. 2012;366:250-7.

19. Willie CK, Tzeng YC, Fisher JA, Ainslie PN. Integrative regulation of human brain blood flow. J Physiol. 2014;592(5):841-59.

20. Hoiland RL, Fisher JA, Ainslie PN. Regulation of the cerebral circulation by arterial carbon dioxide. Compr Physiol. 2019;9:1101-54.

21. Ainslie PN, Duffin J. Integration of cerebrovascular $\mathrm{CO}_{2}$ reactivity and chemoreflex control of breathing: mechanisms of regulation, measurement, and intepretation. Am J Physiol Regul Integr Comp Physiol. 2009;296:R1473-95.

22. Baumgartner $\mathrm{RW}$, Regard $\mathrm{M}$. Role of impaired $\mathrm{CO}_{2}$ reactivity in the diagnosis of cerebral low flow infarcts. J Neurol Neurosurg Psychiatry. 1994;57:814-7.

23. Guennec LL, Cholet C, Huang F, Schmidt M, Brechot N, Hekimian G, et al. Ischemic and hemorrhagic brain injury during venoarterial-extracorporeal membrane oxygenation. Ann Intensive Care. 2018;8:129.

24. Sundgreen C, Larsen FS, Herzog TM, Knudsen GM, Boesgaard S, Aldershvile J. Autoregulation of cerebral blood flow in patients resuscitated from cardiac arrest. Stroke. 2001;32:128-32.

25. Kilgannon $\mathrm{JH}$, Hunter BR, Puskarich MA, et al. Partial pressure of arterial carbon dioxide after resuscitation from cardiac arrest and neurological outcome: a prospective multi-center protocol-directed cohort study. Resuscitation. 2019;135:212-20.

26. Tolins ML, Henning DJ, Gaieski DF, Grossestreuer AV, Jaworski A, Johnson NJ. Initial arterial carbon dioxide tension is associated with neurological outcome after resuscitation from cardiac arrest. Resuscitation. 2017;114:53-8.

27. Giller CA, Bowman G, Dyer H, Mootz L, Krippner W. Cerebral arterial diameters during changes in blood pressure and carbon dioxide during craniotomy. Neurosurgery. 1993;32:737-41.

28. Alkire MT. Quantitative EEG correlations with brain glucose metabolic rate during anesthesia in volunteers. Anesthesiology. 1998;89:323-33.

29. Mutch WAC, El-Gabalawy R, Girling L, Kilborn K, Jacobsohn E. End-tidal hypocapnia under anesthesia predicts postoperative delirium. Front Neurol. 2018;9:678.

30. Ji B, Ündar A. Comparison of perfusion modes on microcirculation during acute and chronic cardiac support: is there a difference? Perfusion. 2007:22:115-9.

31. Ündar A, Eichstaedt HC, Masai T, et al. Comparison of six pediatric cardiopulmonary bypass pumps during pulsatile and nonpulsatile perfusion. J Thorac Cardiovasc Surg. 2001;122:827-9.

32. Floras JS, Rao V, Billia F. To pulse or not to pulse, is that the question? Circulation. 2015;132:2293-6.

33. Ingyinn M, Lee J, Short BL, Viswanathan M. Venoarterial extracorporeal membrane oxygenation impairs basal nitric oxide production in cerebral arteries of newborn lambs. Pediatr Crit Care Med. 2000;1:161-5.

34. Grubhofer G, Mares P, Rajek A, et al. Pulsatility does not change cerebral oxygenation during cardiopulmonary bypass. Acta Anaesthesiol Scand. 2000;44:586-91.

35. Smielewski P, Kirkpatrick P, Minhas P, Pickard JD, Czosnyka M. Can cerebrovascular reactivity be measured with near-infrared spectroscopy? Stroke. 1995;26:2285-92.

36. Grubhofer G, Plöchl W, Skolka M, Czerny M, Ehrlich M, Lassnigg A. Comparing Doppler ultrasonography and cerebral oximetry as indicators for shunting in carotid endarterectomy. Anesth Analg. 2000;91:1339-44.

37. Lundar T, Lindegaard KF, Frøysaker T, et al. Cerebral carbon dioxide reactivity during nonpulsatile cardiopulmonary bypass. Ann Thorac Surg. 1986;41:525-30.

38. Mariappan R, Mehta J, Chui J, Manninen P, Venkatraghavan L. Cerebrovascular reactivity to carbon dioxide under anesthesia: a qualitative systematic review. J Neurosurg Anesthesiol. 2015;27:123-35.

39. Davis MJ, Hill MA. Signaling mechanisms underlying the vascular myogenic response. Physiol Rev. 1999;79:387-423.

40. Ainslie PN, Hoiland RL. Transcranial Doppler ultrasound: valid, invalid, or both? J Appl Physiol. 2014;117:1081-3.
41. Battisti-Charbonney A, Fisher J, Duffin J. The cerebrovascular response to carbon dioxide in humans. J Physiol. 2011;589:3039-48.

42. Rozet I, Vavilala MS, Lindley AM, Visco E, Treggiari M, Lam AM. Cerebral autoregulation and $\mathrm{CO}_{2}$ reactivity in anterior and posterior cerebral circulation during sevoflurane anesthesia. Anesth Analg. 2006;102:560-4.

43. Willie CK, Macleod DB, Shaw AD, et al. Regional brain blood flow in man during acute changes in arterial blood gases. J Physiol. 2012;590:3261-75.

44. Bellapart J, Chan GSH, Tzeng YC, et al. The effect of ventricular assist devices on cerebral blood flow and blood pressure fractality. Physiol Meas. 2011;32: 1361-72.

45. Meng L, Gelb AW. Regulation of cerebral autoregulation by carbon dioxide. Anesthesiology. 2015;122:196-205.

46. Peebles KC, Ball OG, MacRae BA, Horsman HM, Tzeng YC. Sympathetic regulation of the human cerebrovascular response to carbon dioxide. J Appl Physiol. 2012;113:700-6.

47. Przybylowski T, Bangash MF, Reichmuth K, Morgan BJ, Skatrud JB, Dempsey JA. Mechanisms of the cerebrovascular response to apnea in humans. J Physiol. 2003;548:323-32.

48. Cornwell WK, Tarumi T, Stickford A, et al. Restoration of pulsatile flow reduces sympathetic nerve activity among individuals with continous-flow left ventricular assist devices. Circulation. 2015:132:2316-22.

49. Rubanyi GM, Romero JC, Vanhoutte PM. Flow-induced release of endothelium-derived relaxing factor. Am J Phys. 1986;19:H1145-9.

50. Raignault A, Bolduc V, Lesage F, Thorin E. Pulse pressure-dependent cerebrovascular eNOS regulation in mice. J Cereb Blood Flow Metab. 2017; 37:413-24.

51. Markham DW, Fu Q, Palmer MD, et al. Sympathetic neural and hemodynamic responses to upright tilt in patients with pulsatile and nonpulsatile left ventricular assist devices. Circ Heart Fail. 2013;6:293-9.

52. Johnsson P, Messeter K, Ryding E, Kugelberg J, Stahl E. Cerebral vasoreactivity to carbon dioxide during cardiopulmonary perfusion at normothermia and hypothermia. Ann Thorac Surg. 1989:48:769-75.

53. Severdija EE, Vranken NP, Simons AP, et al. Hemodilution combined with hypercapnia impairs cerebral autoregulation during normothermic cardiopulmonary bypass. J Cardiothorac Vasc Anesth. 2015;29:1194-9.

54. Tu YK, Liu HM. Effects of isovolemic hemodilution on hemodynamics, cerebral perfusion, and cerebral vascular reactivity. Stroke. 1996;27:441-5.

55. Bush AM, Borzage MT, Choi S, et al. Determinants of resting cerebral blood flow in sickle cell disease. Am J Hematol. 2016;91:912-7.

56. Kaisti KK, Langsjö JW, Aalto S, et al. Effects of sevoflurane, propofol, and adjunct nitrous oxide on regional cerebral blood flow, oxygen consumption, and blood volume in humans. Anesthesiology. 2003;99:603-13.

57. Klein KU, Fukui K, Schramm P, et al. Human cerebral microcirculation and oxygen saturation during propofol-induced reduction of bispectral index. $\mathrm{Br}$ J Anaesth. 2011;107:735-41.

58. Strebel S, Kaufmann M, Guardiola PM, Schaefer HG. Cerebral vasomotor responsiveness to carbon dioxide is preserved during propofol and midazolam anesthesia in humans. Anesth Analg. 1994;78:884-8.

59. Maekawa T, Cho S, Fukusaki M, Shibata O, Sumikawa K. Effects of clonidine on human middle cerebral artery flow velocity and cerebrovascular $\mathrm{CO}_{2}$ response during sevoflurane anesthesia. J Neurosurg Anesthesiol. 1999;3: $173-7$.

60. Cho S, Fujigaki T, Uchiyama Y, Fukusaki M, Shibata O, Sumikawa K. Effects of sevoflurane with and without nitrous oxide on human cerebral circulation. Anesthesiology. 1996;85:755-60.

61. Myburgh JA, Upton RN, Grant C, Martinez A. The cerebrovascular effects of adrenaline, noradrenaline and dopamine infusions under propofol and isoflurane anaesthesia in sheep. Anaesth Intensive Care. 2002;30:725-33.

62. Pagel PS, Hettrick DA, Warltier DC. Influence of levosimendan, pimobendan, and milrinone on the regional distribution of cardiac output in anaesthestized dogs. Br J Pharmacol. 1996;119:609-15.

63. Schalen W, Messeter $\mathrm{K}$, Nordström $\mathrm{CH}$. Cerebral vasoreactivity and the prediction of outcome in severe traumatic brain lesions. Acta Anaesthesiol Scand. 1991;35:113-22

64. Schnaubelt S, Sulzgruber P, Menger J, Skhirtladze-Dworschak K, Sterz F, Dworschak M. Regional cerebral oxygen saturation during cardiopulmonary resuscitation as a predictor of return of spontaneous circulation and favourable outcome - a review of the current literature. Resuscitation. 2018; 125:39-47.

65. Skhirtladze K, Mora B, Moritz A, Birkenberg B, Ankersmit HJ, Dworschak M. Impaired recovery of cardiac output and mean arterial pressure after 
successful defibrillation in patients with low left ventricular ejection fraction. Resuscitation. 2010;81:1123-7.

66. Prough DS, Rogers AT, Stump DA, et al. Cerebral blood flow decreases with time whereas cerebral oxygen consumption remains stable during hypothermic cardiopulmonary bypass in humans. Anesth Analg. 1991;72:161-8.

67. Dworschak M. Is extracorporeal cardiopulmonary resuscitation for out-ofhospital cardiac arrest superior compared with conventional resuscitation? Crit Care Med. 2013;41:1365-6.

68. Kim YM, Youn CS, Kim SH, Lee BK, Cho IS, Cho GC, et al. Adverse events associated with poor neurological outcome during targeted temperature management and advanced critical care after out-of-hospital cardiac arrest. Crit Care. 2015;19:282.

69. Kane N, Grocott L, Kandler R, Lawrence S, Pang C. Hyperventilation during electroencephalography: safety and efficacy. Seizure. 2014;23:129-34.

\section{Publisher's Note}

Springer Nature remains neutral with regard to jurisdictional claims in published maps and institutional affiliations.

Ready to submit your research? Choose BMC and benefit from:

- fast, convenient online submission

- thorough peer review by experienced researchers in your field

- rapid publication on acceptance

- support for research data, including large and complex data types

- gold Open Access which fosters wider collaboration and increased citations

- maximum visibility for your research: over $100 \mathrm{M}$ website views per year

At $\mathrm{BMC}$, research is always in progress.

Learn more biomedcentral.com/submissions 